\title{
GERAKAN LITERASI ISLAMIYAH MELALUI PROGRAM TAKLIM DAN TARBIYAH DI KECAMATAN TIWORO TENGAH KABUPATEN MUNA BARAT
}

\section{THE ISLAMIC LITERACY MOVEMENT THROUGH THE TAKLIM AND TARBIYAH PROGRAM IN CENTRAL TIWORO SUBDISTRICT WEST MUNA REGENCY}

\author{
Khaerul Aqbar \\ Sekolah Tinggi Ilmu Islam dan Bahasa Arab (STIBA) Makassar \\ Email: khaerul@stiba.ac.id

\section{Muhammad Taufan Djafri} \\ Sekolah Tinggi Ilmu Islam dan Bahasa Arab (STIBA) Makassar \\ Email: muhammadtaufan@stiba.ac.id
}

\section{Ariesman}

Sekolah Tinggi Ilmu Islam dan Bahasa Arab (STIBA) Makassar Email: ariesman@stiba.ac.id

\begin{tabular}{ll}
\hline Keywords : & \multicolumn{1}{c}{ ABSTRACT } \\
Tarbiyah, Qur'aniyah, KKN & The purpose of the Real Work Lecture (KKN) of STIBA Makassar \\
Batch IV is to carry out community service as a pillar of "Tri \\
Dharma Perguruan Tinggi". The method of implementation of the \\
service program begins by mapping the problems and needs of the \\
community using SOAR Analysis. After the analysis is done, the work \\
program is arranged according to the needs of the community. The \\
successful work program was Taklim Qur'aniyah Virtual for Youth, \\
Taklim Qur'aniyah Virtualfor Mothers, Tarbiyah Qur'aniyah Virtual \\
for Fathers. All these programs have shown significant initial results \\
in accordance with the objectives of the KKN of STIBA Makassar \\
that have been proclaimed, and will be continued by the Department \\
of Dakwah and Cadreization of DPD Wahdah Islamiyah Muna \\
Barat.
\end{tabular}


Diterima: 17 Oktober 2021; Direvisi: 17 Desember 2021; Disetujui: 17 Desember 2021; Tersedia online: 31 Desember 2021

How to cite: Khaerul Aqbar, Muhammad Taufan Djafri, Ariesman, "Gerakan Literasi Islamiyah Melalui Program Taklim dan Tarbiyah di Kecamatan Tiworo Tengah Kabupaten Muna Barat", WAHATUL MUJTAMA': Jurnal Pengabdian Masyarakat Vol. 2, No. 2 (2021): 155-163. doi: 10.36701/wahatul.v2i2.434.

\section{PENDAHULUAN}

Kecamatan Tiworo Tengah adalah salah satu dari 11 kecamatan yang berada di Kabupaten Muna Barat ${ }^{1}$. Luas wilayah Kecamatan Tiworo Tengah adalah 82,38 $\mathrm{km}^{2}$ atau 8,22\% dari luas Kabupaten Muna Barat. Kecamatan Tiworo Tengah terdiri dari 8 kelurahan yaitu Wanseriwu, Langku-Langku, Mekar Jaya, Wapae, Labokolo, Lakabu, Momuntu dan Suka Damai. ${ }^{2}$

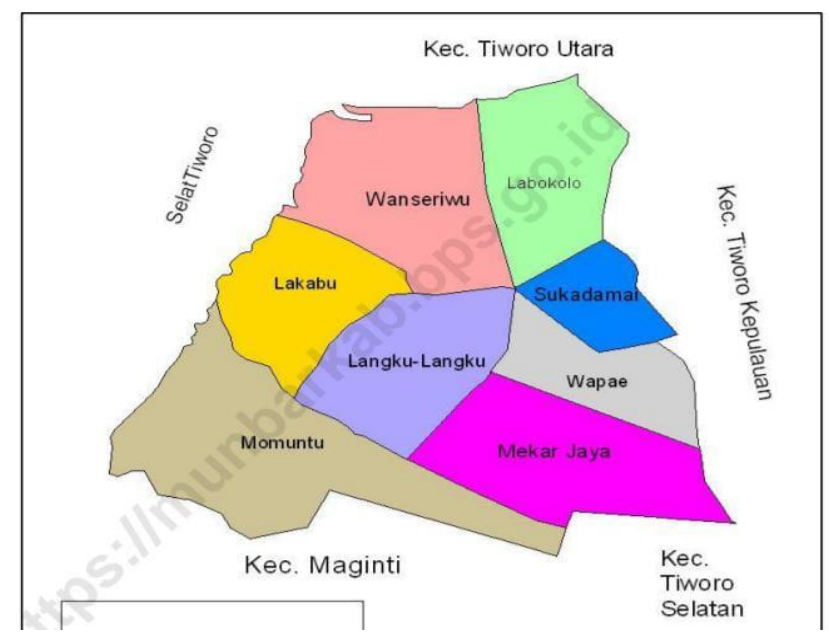

Gambar 1. Peta administrasi Kec.Tiworo Tengah ${ }^{3}$

Secara astronomis, Kecamatan Tiworo Tengah terletak di bagian selatan pulau Muna. Secara geografis, Kecamatan Tiworo Tengah terletak di bagian selatan garis khatulistiwa, memanjang dari utara ke selatan di antara 04 52'226” 04'83'514" Lintang Selatan dan membentang dari barat ke timur di antara $122^{\circ} 32^{\prime} 194^{\prime \prime}$ - 12240’079” Bujur Timur. Batas wilayah administrasi Kecamatan Tiworo Tengah adalah sebagai berikut: sebelah utara berbatasan dengan kecamatan Tiworo Utara; sebelah timur berbatasan dengan Tiworo Kepulauan; sebelah selatan berbatasan dengan Kecamatan Maginti; dan sebelah barat berbatasan dengan Selat Tiworo. Jumlah penduduk Kecamatan Tiworo Tengah pada tahun 2019 adalah 7318

'Wikipedia, "Wikipedia," Wikipedia, 2021, https://id.wikipedia.org/wiki/Kabupaten_Muna_Barat. (Diakses pada tanggal 13 Oktober 2021).

${ }^{2}$ Badan Pusat Statistik kabupate Muna, Kecamatan Tiworo Tengah Dalam Angka (Muna Barat, 2020), h. 22.

${ }^{3}$ Badan Pusat Statistik kabupate Muna, Kecamatan Tiworo Tengah Dalam Angka (Muna Barat, 2020), h.iii. 
jiwa, ${ }^{4}$ terdapat 11 buah masjid dan 12 buah musalla, yang tersebar di dua desa yaitu 10 buah di Desa Mekar Jaya dan 2 buah di Desa Wapea, ${ }^{5}$ dan terdapat 9 unit Taman Pendidikan Al-Qur'an (TPA/TPQ). ${ }^{6}$ Berdasarkan uraian singkat profil Kecamatan Tiworo Tengah di atas, dapat disimpulkan bahwa rasio masjid dengan jumlah penduduk serta luas wilayah belum berimbang dan juga pembinaan anak-anak TPA/TPQ masih minim. Pelaksanaan program kerja KKN STIBA Makassar Angkatan IV di Tiworo Tengah meskipun dilaksanakan secara virtual dinilai berpotensi dapat memberikan kontribusi bagi pengembangan kegiatan pembinaan keagamaan di tengah masyarakat. Oleh karena itu, ditetapkan tujuan pelaksanaan KKN STIBA Makassar sebagai berikut: (1) untuk mengambil peran dalam membantu pemerintah Kecamatan Tiworo Tengah untuk menghidupkan kegiatan pembinaan keagamaan; (2) untuk meningkatkan kesadaran sosial dan dakwah mahasiswa STIBA Makassar dalam berkontribusi pada peningkatan Sumber Daya Manusia (SDM) masyarakat di Kecamatan Tiworo Tengah; dan (3) menunaikan kewajiban STIBA Makassar sebagai perguruan tinggi keagamaan Islam dalam melaksanakan Tri Dharma Perguruan Tinggi pada pilar pengabdian masyarakat.

Sebelum menetapkan program kerja KKN di Kecamatan Tiworo Tengah, dimana pada tahun ini bekerja sama dengan Dewan Pimpinan Daerah (DPD) Wahdah Islamiyah Kabupaten Muna Barat yang selanjutnya dalam tulisan ini akan disebut dengan DPD Muna Barat, terlebih dahulu dilakukan survei lapangan dan koordinasi dengan DPD Muna Barat untuk keperluan analisis kebutuhan program pemberdayaan masyarakat, dengan mengaplikasikan instrumen sederhana dalam memetakan kebutuhan, yaitu analisis SOAR. Hasil analisis SOAR secara ringkas adalah sebagai berikut:

1. Strenght, yaitu keadaan masyarakat secara umum yang religius dan masih mempertahankan tradisi yang baik, terdapatnya TPA/TPQ di setiap kelurahan, jumlah penduduk usia produktif yang banyak, kondisi mahasiswa KKN telah dibekali dengan pelatihan yang menunjang pelaksanaan kegiatan keagamaan di masyarakat.

2. Oppurtunities, yaitu adanya dukungan dari DPD Muna Barat yang berkedudukan di Kecamatan Tiworo Tengah, adanya dukungan pemerintah setempat, tersedianya akses transportasi dan informasi.

3. Aspiration, yaitu program dan sarana pembinaan keislaman masih minim, khususnya usia remaja, kegiatan keagamaan yang masih perlu ditingkatkan kualitasnya di wilayah Kecamatan Tiworo Tengah, dan kurangnya unit Taman Kanak-kanak/Pendidikan Al-Qur'an (TK/TPA) para santri di wilayah Kecamatan Tiworo Tengah.

4. Result, yaitu masyarakat memiliki kesadaran untuk belajar Islam secara runut, terwujudnya generasi muda yang dekat dengan nilai Islam dan memiliki

${ }^{4}$ IBadan Pusat Statistik kabupate Muna, Kecamatan Tiworo Tengah Dalam Angka (Muna Barat, 2020), h. 33.

${ }^{5}$ Badan Pusat Statistik kabupate Muna, Kecamatan Tiworo Tengah Dalam Angka (Muna Barat, 2020), h. 65.

${ }^{6}$ Badan Pusat Statistik kabupate Muna, Kecamatan Tiworo Tengah Dalam Angka (Muna Barat, 2020), h. 56. 
perhatian terhadap kondisi umat, dan terwujudnya generasi Qur'ani dengan berdirinya TTK/PA di setiap masjid dan musalla.

Dengan memperhatikan analisis SOAR di atas dan mempertimbagkan jumlah mahasiswa KKN, ditetapkan tiga program kerja KKN STIBA Makassar Angkatan IV di Kecamatan Tiworo Tengah, yaitu: Taklim Qur'aniyah Remaja, Taklim Qur'aniya Ibu-ibu dan Tarbiyah Qur'aniyah Bapak-bapak. Semua program kerja ini dilaksanakan secara virtual.

Pelaksanaan program KKN pengabdian dengan pendekatan Al-Quran telah dilakukan sebelumnya oleh mahasiswa KKN STIBA Makassar di beberapa daerah sebagai berikut:

1. Pengabdian yang dilakukan di Desa Kalabbirang, Kecamatan Bantimurung, Kabupaten Maros, Sulawesi Selatan, dengan tema "Mewujudkan Masyarakat Qur'ani" dimana program yang dilaksanakan bertujuan untuk mendekatkan masyarakat kepada Al-Qur'an baik secara bacaan maupun pengamalan. Semua program berjalan dengan baik, terlihat dengan adanya peningkatan kualitas bacaan Al-Qur'an masyarakat yang mengikuti program KKN ini. ${ }^{7}$

2. Pengabdian mahasiswi KKN STIBA di Desa Tukamase. Kecamatan Bantimurung. Dengan mengusung program dirasah qur'aniyah yaitu serangkaian kegiatan pengajaran Al-Qur'an dan taklim keislaman serta Bahasa Arab juga program wakaf Al-Qur'an, kegiatan ini mendapat dukungan dari masyarakat dan pemerintah setempat karena membantu mengatasi buta aksara Al-Qur'an pada masyarakat yang juga merupakan program pemerintah daerah setempat. Pasca program dilaksanakan terlihat adanya perbaikan bacaan AlQur'an dan pemahaman masyarakat yang lebih dekat pada Al-Qur'an. ${ }^{8}$

3. Pengabdian yang dilakukan di Kecamatan Manggala, Kota Makassar, Sulawesi Selatan dengan tema "Mewujudkan Masyarakat Qur'ani"dimana program yang dilaksanakan bertujuan untuk mendekatkan remaja kepada Al-Qur'an baik secara bacaan, hafalan maupun pengamalan. Semua program berjalan dengan baik, terlihat dengan adanya peningkatan kualitas bacaan dan hafalan Al-Qur'an remaja yang mengikuti program $\mathrm{KKN}$ ini. ${ }^{9}$

Dengan melihat bahwa program pengabdian telah dilaksanakan terlebih dahulu di beberapa tempat di wilayah Sulawesi Selatan, pengabdian KKN STIBA Makassar Angkatan IV juga disebar ke beberapa daerah, salah satunya di Kecamatan Tiworo Tengah, Kabupaten Muna Barat, dengan tujuan untuk menghidupkan pengajaran Al-Qur'an dan pembinaan masyarakat Islami.

7 Sartini La Mbadjo and Ahmad Hanafi, "Mewujudkan Masyarakat Qurani Di Desa Kalabbirang Melalui Program KKN Stiba Makassar," WAHATUL MUJTAMA': Jurnal Pengabdian Masyarakat 1, no. 2 (2020): 157-73, doi:https://doi.org/10.36701/wahatul.v1i2.255.

${ }^{8}$ Iskandar Iskandar and M Amirullah, "Pelaksanaan Dirasah Quraniyah Sebagai Upaya Peningkatan Kualitas Baca Al-Qur'an Di Desa Tukamase," WAHATUL MUJTAMA': Jurnal Pengabdian Masyarakat 1, no. 1 (2020): 42-53, doi:https://doi.org/10.36701/wahatul.v1i1.135.

9 Rachmat bin Badani Tempo, Ahmad Syaripudin, and Irsyad Rafi, "Pembinaan Masyarakat Qur'ani Di Kecamatan Manggala Melalui KKN STIBA Makassar," WAHATUL MUJTAMA': Jurnal Pengabdian Masyarakat Vol. 2, no. No. 1 (2021), doi:https://journal.stiba.ac.id/index.php/wahatul/article/view/340/205. 


\section{PEMBAHASAN}

\section{Taklim Qur'aniyah Remaja Virtual}

Taklim Qur'aniyah Remaja bertujuan untuk berbagi ilmu dan memberikan pemahaman tentang ilmu agama berdasarkan Al-Quran dan Sunah sehingga bisa menambah wawasan dan keimanan khusunya kepada kaum remaja. Kegiatan ini juga bermanfaat dalam menambah wawasan mahasiswa KKN STIBA Makassar di dalam mengelola dan mengisi taklim dalam kegiatan virtual (online).

Kegiatan Taklim Qur'aniyah Remaja dimulai setelah salat Isya menggunakan aplikasi zoom dan diikuti oleh 7 peserta. Taklim dibuka dengan menyebut nama Allah swt., berselawat kepada Rasulullah saw., dan menyapa peserta satu persatu lalu dilanjutkan dengan penyampaian materi berupa pesanpesan moral dari Al-Qur'an dan hadis Rasulullah dan cara aplikasinya dalam kehidupan sehari hari. Di akhir kegiatan, peserta diberikan kesempatan untuk bertanya tentang materi yang telah disampaikan. Taklim ditutup dengan ucapan terima kasih kepada peserta taklim yang telah hadir dan berdoa semoga Allah swt. menerima dan membalas pahala atas kegiatan majelis yang dilakukan, dan terakhir menutup dengan doa kafarat majelis, kemudian pamit keluar dari zoom.

Peserta sangat antusias mengikuti kegiatan ini. Para peserta dapat menyimak materi dengan baik sehingga dapat menambah wawasan ilmu agama mereka. Di antara tema yang disampaikan adalah pentingya menuntut ilmu agama, beramal saleh dan memperbanyak berdoa kepada Allah swt., serta penjelasan tentang keutamaan pemuda yang terpaut hatinya dengan masjid yang akan mendapatkan naungan Allah swt. di Padang Mahsyar di akhirat kelak sehingga hal ini diharapkan memberikan semangat kepada para peserta dalam berlomba-lomba melaksaanakan kebaikan.

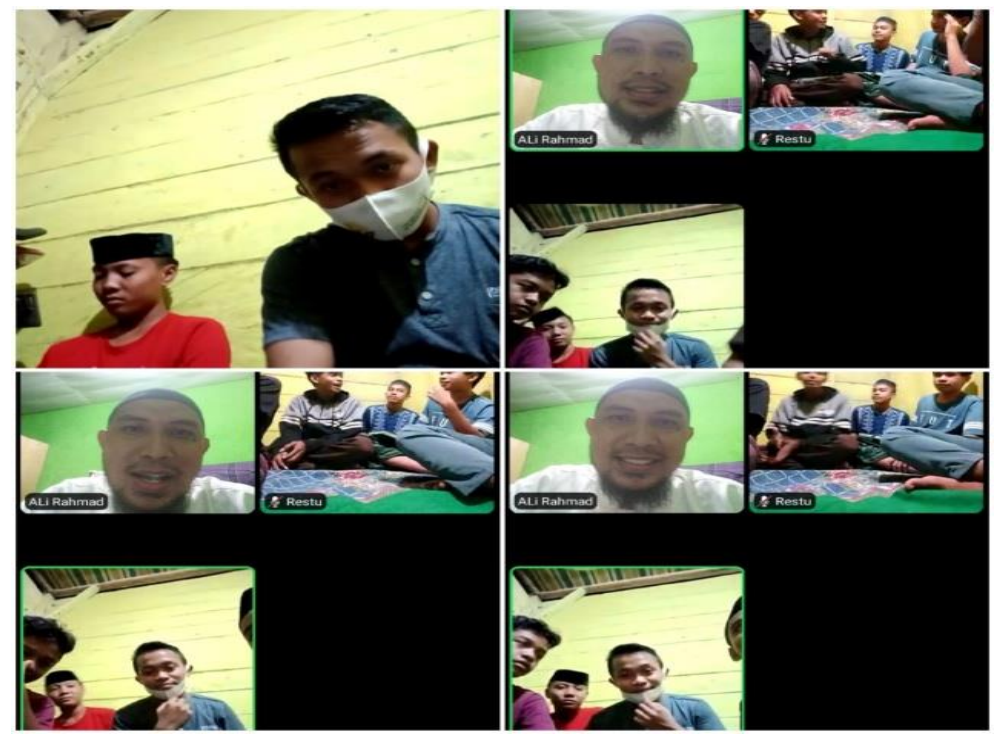

Gambar 2. Pelaksanaan Taklim Remaja Virtual

\section{Taklim Qur'aniyah Ibu-ibu Virtual}


Kegiatan Taklim Qur'aniyah Ibu-ibu dilaksanakan setiap pekannya di hari Senin, Selasa, Jum'at dan Sabtu bakda Salat Asar sampai selesai. Kegiatan Ini bertujuan untuk berbagi ilmu dan memberikan pemahaman tentang ilmu agama berdasarkan Al-Quran dan Sunah sehingga bisa menambah wawasan dan keimanan. Kegiatan ini juga bermanfaat menambah wawasan mahasiswa KKN STIBA Makassar di dalam mengelola dan mengisi taklim dalam kegiatan virtual online.

Kegiatan ini diikuti oleh 25 orang Ibu-ibu, dimulai setelah salat Asar melalui aplikasi zoom cloud meeting. Taklim diawali dengan memuji Allah swt., berselawat kepada Rasulullah saw., lalu menyapa peserta. Taklim diisi dengan penyampaian kajian tematik dari ayat-ayat Al-Quran dan hadis-hadis Rasulullah. Akhir kegiatan adalah sesi tanya-jawab terkait materi, ucapan terima kasih kepada peserta taklim yang telah hadir, berdoa semoga Allah swt. menerima dan memberi pahala atas kegiatan majelis yang dilakukan, lalu menutup kegitan taklim dengan doa kafarātul-majlīs, kemudian pamit keluar dari zoom.

Peserta sangat antusias mengikuti kegiatan ini. Ppara peserta dapat menyimak materi dengan baik sehingga dapat menambah wawasan ilmu agama mereka. Di antara tema yang disampaikan adalah pentingya menuntut ilmu agama, beramal saleh dan memperbanyak berdoa kepada Allah swt. sehingga hal ini diharapkan memberikan semangat kepada para peserta dalam berlombalomba melaksanakan kebaikan.

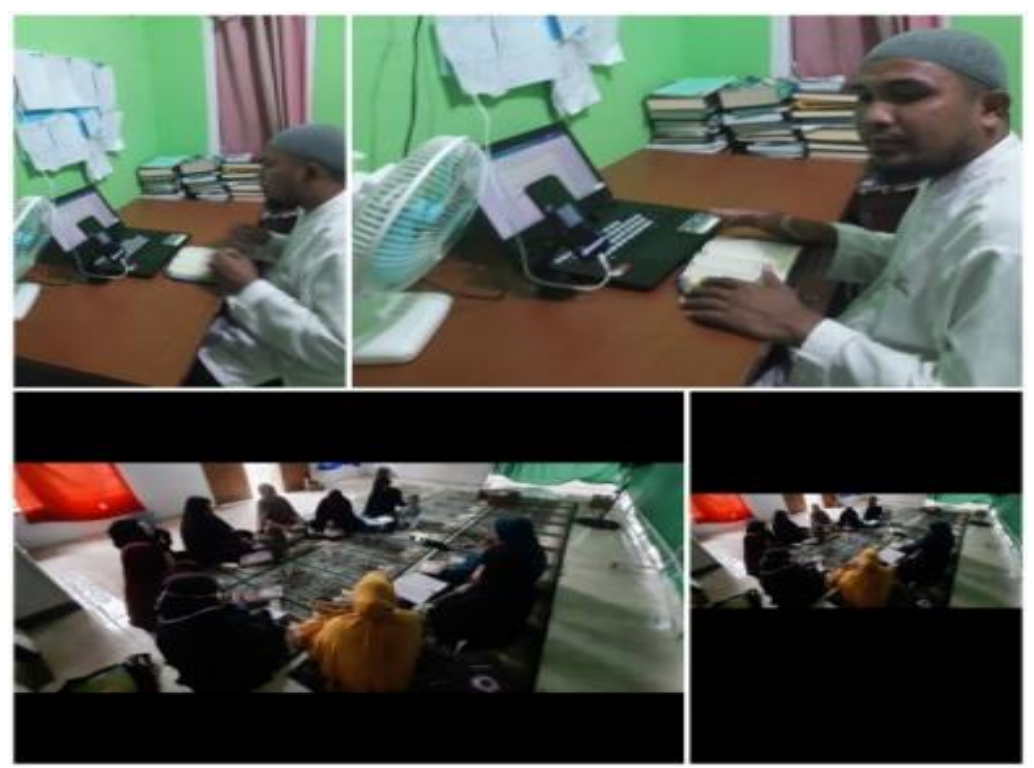

Gambar 3. Pelaksanaan Taklim Ibu Ibu Virtual

\section{Tarbiyah Qur'aniyah Virtual}

Tarbiyah Qur'aniyah adalah sebuah metode pembinaan umat yang dilakukan untuk melahirkan pribadi-pribadi muslim yang istimewa/berkualitas menuju 
tegaknya syariat Islam. ${ }^{10}$ Pada awalnya, kegiatan ini dikenal dengan nama Tarbiyah Islamiyah, ${ }^{11}$ kemudian dewasa ini dipopulerkan dengan nama Tarbiyah Qur'aniyah oleh oleh salah seorang murabbi (pembina kelompok Tarbiyah) senior dari ormas Wahdah Islamiyah, Muhammad Kasim. ${ }^{12}$

Adapun ruang lingkup program ini adalah: 1. Tarbiyah Ruhiyyah yang meliputi salat jemaah, perbaikan bacaan Al-Qur'an, arahan-arahan murabbi, tazkiyatun nafs, menjenguk anggota kelompok yang sakit, mengunjungi anggota kelompok yang perlu dimotivasi, mabit (bermalam bersama) dengan tujuan untuk mengamalkan sunah-sunah di waktu malam sampai pagi hari, di antaranya Salat Tahajud bersama, sahur bersama, zikir pagi, buka puasa Senin-Kamis Bersama, dimana kegiatan mabit ini biasanya dilakukan sekali atau dua kali dalam setahun; 2. Tarbiyah Tsaqafiyah (wawasan keilmuan) yang meliputi; Kajian Islam Tematik, Syarah Hadis Adab-adab Seorang Muslim, Menghafal Al-Qur'an dan Hadis, latihan kultum, problem solving, telaah kitab, penugasan menghadiri majelis taklim; 3 . Tarbiyah Jasadiyah (fisik) yang meliputi olahraga, check-up kesehatan dan rihlah, dimana kegiatan ini biasanya dilakukan sekali dalam setahun, kecuali olahraga yang dianjurkan setiap pekan secara mandiri. ${ }^{13}$ Jumlah ideal peserta kelompok Tarbiyah Qur'aniyah adalah 10 sampai 15 orang, untuk memudahkan pengontrolan dan pembinaan.

Program Tarbiyah Qur'aniyah virtual ini bertujuan untuk memberikan pembinaan rohani, tsaqafiyah dan jasadiyah kepada masyarakat. Kegiatan ini juga memberi wawasan kepada Mahasiswa KKN STIBA Makassar Angkatan IV agar bisa memiliki kemampuan menarbiyah dengan baik dan benar sesuai dengan metode yang tepat dan penyampaian yang benar.

Kegiatan Tarbiyah Qur'aniyah terbagi dalam tiga kegiatan, yaitu kegiatan awal, kegitan inti dan kegiatan akhir. Kegiatan awal dilakukan selama 45 menit, diisi dengan, saling sapa, absensi, tahsinnul qirā'ah (perbaikan bacaan Al-Qur'an), setoran hafalan Al-Qur'an atau hadis. Kegiatan inti dilakukan selama 75 menit, disi dengan taujihāt murabbi (arahan pembina), kajian dinul-Islam, syarah hadis, problem soving. Kegiatan akhir dilakukan selama 10 menit diisi dengan arahan untuk berinfak, istirahat dan nasihat penutp dan pembacaan doa kafarātul-majlìs. ${ }^{14}$

Meskipun kegiatan tarbiyah ini dilakukan secara virtual karena kendala pandemi Covid-19 dan tidak seefektif dengan Tarbiyah secara offline, tetapi peserta

10 Tim Mawad Tarbiyah Departemen Kaderisasi DPP Wahdah Islamiyah, Mawad Tarbiyah Marhalah Ta'rif I (Makassar: Departemen Kaderisasi DPP Wahdah Islamiyah, 2019), h. $19-24$.

${ }^{11}$ Nuzul Haq and Suryani Mursalin, "Penerapan Tarbiyah Islamiyah Dalam Pembinaan Akhlak Siswa Sekolah Menengah Pertama Islam Terpadu Wahdah Islamiyah Makassar," Tomalebbi, Jurnal Pemikiran, Penelitian Hukum, Pendidikan Pancasila Dan Kewarganegaraan Vol. III, no. No. I (2016), h. 66.

${ }^{12}$ Departemen Infokom Wahdah Islamiyah Jawa Tengah, "Tabligh Akbar 1 Rumah 1 Hafidz Al-Qur'an Untuk Kejayaan Indonesia” (Indonesia, 2021), https://www.youtube.com/watch?v=KGTp37W1HaE\&t=7s.

${ }^{13}$ DPP, Mawad Tarbiyah Marhalah Ta'rif I.h. 13-14.

${ }^{14}$ LKPDM DPP Wahdah Islamiyah, Materi Diklat Murabbi C, Cet. I (Makassar: LKPDM DPP Wahdah Islamiyah, 2014). 
tetap bisa meraih sebagian esensi dari Tarbiyah Qur'aniyah terutama dalam hal menjaga dan mengarahkan binaan dalam situasi pandemi Covid-19 dalam menjaga keimanan dan peningkatan wawasan keislaman.

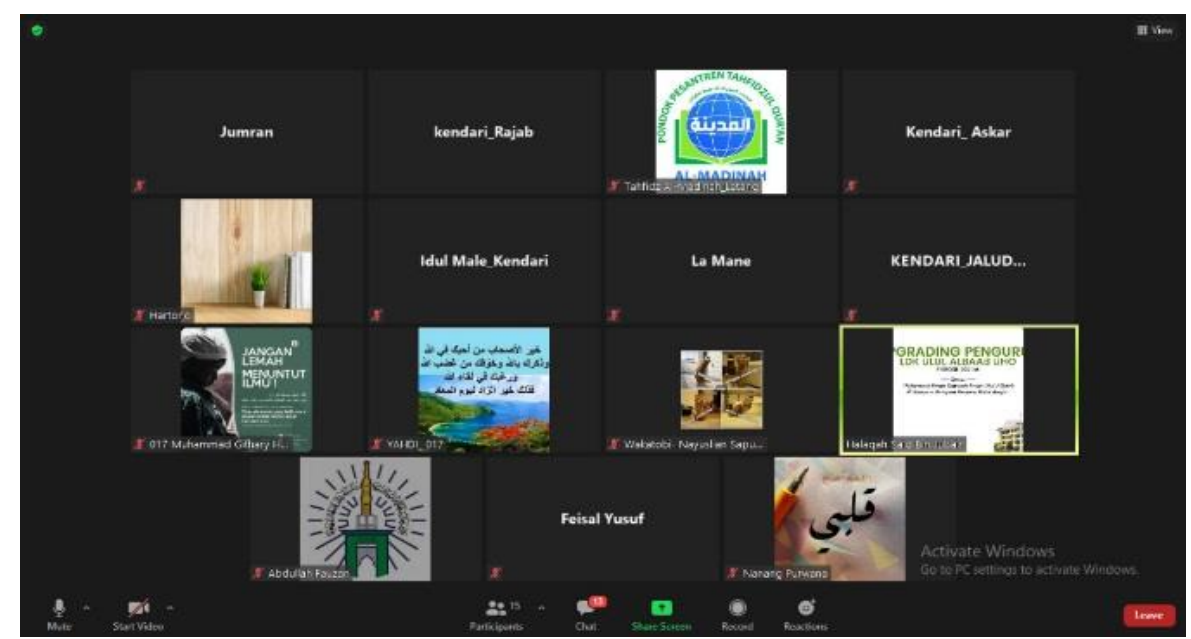

Gambar 4. Kegiatan Tarbiyah Qur'aniyah Virtual.

\section{KESIMPULAN}

Program Kuliah Kerja Nyata (KKN) STIBA Makassar Angkatan IV ini adalah wujud pengabdian kepada masyarakat yang merupakan pilar dari Tri Dharma Perguruan Tinggi. Program kerja yang dilaksanakan oleh mahasiswa KKN STIBA Makassar Angkatan IV di Kecamatan Tiworo Tengah di antaranya adalah: Pembinaan Remaja dalam bentuk kegiatan Taklim Qur'aniyah Remaja Virtual, pembinaan majelis taklim dalam bentuk kegiatan Taklim Qur'aniyah Ibu-ibu secara virtual, Pembinaan bapak-bapak dalam bentuk kegiatan Tarbiyah Qur'aniyah Bapak-bapak secara virtual. Semua program tersebut telah menampakkan hasil awal yang cukup signifikan sesuai dengan tujuan KKN yang telah dicanangkan, dan akan dilanjutkan oleh Departemen Dakwah dan Kaderisasi DPD Wahdah Islamiyah Muna Barat.

\section{DAFTAR PUSTAKA}

DPP, LKPDM DPP Wahdah Islamiyah. Materi Diklat Murabbi C. Cet. I. Makassar: LKPDM DPP Wahdah Islamiyah, 2014.

DPP, Tim Mawad Tarbiyah Departemen Kaderisasi DPP Wahdah Islamiyah. Mawad Tarbiyah Marhalah Ta'rif I. Makassar: Departemen Kaderisasi DPP Wahdah Islamiyah, 2019.

Haq, Nuzul, and Suryani Mursalin. "Penerapan Tarbiyah Islamiyah Dalam Pembinaan Akhlak Siswa Sekolah Menengah Pertama Islam Terpadu Wahdah Islamiyah Makassar." Tomalebbi, Jurnal Pemikiran, Penelitian Hukum, Pendidikan Pancasila Dan Kewarganegaraan Vol. III, no. No. I (2016): 6368.

Iskandar, Iskandar, and M Amirullah. "Pelaksanaan Dirasah Quraniyah Sebagai 
- Jurnal — WAHATUL MUJTAMA': Jurnal Pengabdian Masyarakat

WAHATUL Vol. 2, No. 2 (2021): 155-163

Upaya Peningkatan Kualitas Baca Alquran Di Desa Tukamase.” WAHATUL MUJTAMA': Jurnal Pengabdian Masyarakat 1, no. 1 (2020): 42-53. doi:https://doi.org/10.36701/wahatul.v1i1.135.

Mbadjo, Sartini La, and Ahmad Hanafi. "Mewujudkan Masyarakat Qurani Di Desa Kalabbirang Melalui Program KKN STIBA Makassar." WAHATUL MUJTAMA': Jurnal Pengabdian Masyarakat 1, no. 2 (2020): 157-73. doi:https://doi.org/10.36701/wahatul.v1i2.255.

Muna, Badan Pusat Statistik kabupaten. Kecamatan Tiworo Tengah Dalam Angka. Muna Barat, 2020.

Tempo, Rachmat bin Badani, Ahmad Syaripudin, and Irsyad Rafi. "Pembinaan Masyarakat Qur'ani Di Kecamatan Manggala Melalui Kkn Stiba Makassar." WAHATUL MUJTAMA': Jurnal Pengabdian Masyarakat 2, no. No. 1 (2021). doi:https://journal.stiba.ac.id/index.php/wahatul/article/view/340/205.

Tengah, Departemen Infokom Wahdah Islamiyah Jawa. "Tabligh Akbar 1 Rumah 1 Hafidz Al-Qur'an Untuk Kejayaan Indonesia." Indonesia, 2021. https://www.youtube.com/watch?v=KGTp37W1HaE\&t=7s.

Wikipedia. "Wikipedia." Wikipedia,

2021. https://id.wikipedia.org/wiki/Kabupaten_Muna_Barat. 